\title{
A Study on Public Speaking in Korean Education for Chinese Students
}

\author{
Lili Pan \\ Department of Korean Language, College of Oriental Languages \& Culture, Qufu Normal University, Rizhao, China \\ Email: panlili0622@yahoo.com.cn
}

\begin{abstract}
It is necessary to have adequate opportunity to use the foreign language in order to get the language skills, especially the oral expression skills, in the procedure of learning a foreign language. The author uses a method of public speaking in the real lecture in order to provide more opportunities for Chinese students when teaching them Korean. The aim is to encourage the students to have a confidence and increase the interesting on studying Korean, and also to put the knowledge what they learned from the textbook into the practice. The instructors implementing the method need to understand the relevance of public speaking education and to know its processes. In addition to drawing on the best teaching practices, instructors also need continuous support for professional and instructional development in the new teaching area. Actually through the public speaking method, students' reading ability, listening and speaking ability in Korean has been improved to a large degree. Another unexpected result is that the method also creates a platform of exchanging the information among students.
\end{abstract}

Index Terms - Korean education, public speaking, output, effect analysis

\section{INTRODUCTION}

The target of teaching a foreign language is to develop the students' comprehensive skills such as listening, speaking, reading, writing and translating. All of the above skills and other language skills are an interrelated unity of studying a foreign language. In the procedure of teaching Korean in China's university, a phenomenon can be found easily, that is, many students can't understand what they heard in Korean instantly, but can understand easily when reading it, and the most difficult thing for them is to speak in Korean correctly. The reason is that there is a process of change between the printed words and spoken words. However, if students are able to speak something in Korean, they can get the meaning without any difficulties when reading it due to the omission of the process of mental translation, as mentioned by Meimei, Chen (2004, P27), and also can write it down correctly in Korean.

It is necessary to have adequate opportunity to use the foreign language in order to get the language skills, especially the oral expression skills when learning a foreign language. During the period of teaching Korean, or the communication with Korean scholars and friends, the author found that at present the majority of Korean learners are pretty good at Korean listening, reading and writing, but there are some problems in their speaking ability, in particular, to speak Korean accurately and fluently. And the lack of speaking ability will also largely affect the quality of translation in the future. Currently, most students in our Korean department are studying hard to prepare for the middle or high levels of the Korean Language Proficiency Test. It cost them a lot of time and effort to prepare, but very few students take the time to exercise their oral expression. Most of the students rely mainly on classroom teaching to practice speaking, only a small number of students looking for the opportunities to practice speaking Korean after-school.

On the other hand, there are various speech contests for the students of Korean department every year in China. At the time of recommending students to participate in the competition, the author felt that the training of normal oral presentation skills is very necessary. According to the investigation on the graduates of Korean department of our university, it is also found that most of them were not hired when they went to look for a job, because their Korean were not fluent or lack of immediate response when interview. It also made the author recognize that how important for the students of Korean department to improve their listening and speaking abilities in practice. In order to provide more opportunities for students, the method of public speaking is put into practice, and it plays a good role in stimulating the students' enthusiasm and implementing the teaching objectives.

\section{THEORETICAL BACKGROUND}

Traditional teaching model of foreign language focuses on the correct form of language. The comprehensive teaching theory of Wilkins (1976) stressed that the teaching activities must surround with the language form of lessons. First, teachers explain the vocabulary, grammar, sentence patterns and other knowledge points which appeared in the text. And then organize the students to practice them, so as to master the knowledge what they learned. But this method would isolate the point of linguistic knowledge so that the students are often unable to quickly grasp the new language points and grammatical form, even the simple language forms. And the students can master the language forms only 
through a long time of practicing to match the form and language function well.

Because the above language teaching methods can not reach the expected learning effects, teachers should change the approach to provide students with sufficient "comprehensible language input", and encourage students to open their mouth without too much emphasis on the accuracy of language form, but focused on the significance of communication instead (focus on meaning, Krashen 1988), to complete the transmission of information without considering the language errors. Teachers can also adjust the student's language input according to their language level at any time, so that to achieve the aim of not only leaning the correct form of language, but also a success communication. Success Communication depends on the quality of oral expression to a large extent. When the learner fails to communicate with others, they will force them to express more precise, more coherent, and more elegant in foreign language. Swain (1995) pointed that output is a process which leads the learners from the semantic to the syntactic process. Output in practice will force the speaker to pay more attention to express exactly in order to achieve a comprehensible output. Comprehensible output refers that the speaker not only conveys information, but also conveys in accurate, consistent and decent way. Studies of Gass \& Selinker (2001) showed that comprehensible output plays specific four roles for the output of syntax and morphology, namely: Testing hypothesis, Feedback, Automaticity, and Move from semantic processing to syntactic process.

The function and importance of output mentioned above play a more active role for learners, and enable learners to organize language in a high way, also facilitate learners to complete the transition from the state of semantics uncertain understanding to the state of using grammar exactly. The whole process of output will be a process of combining language form, meaning and function, and it is a crucial part in learning a foreign language, learners need to consider which kinds of form can express what they think exactly.

Actually public speaking is an output with high demand. It requires students to conduct extensive reading firstly, then choose the topic what they interest to speak, and using the relevant knowledge of the language points to express in a specific period of time, also be accurate, fluent, and decency. The final stage, that is Q\&A, not only checked the students' listening ability, but also trained their adaptability. Teacher can instruct the students to answer the questions in a simple, targeted way. Public speaking links all aspects of the process of learning language together, including the choice of words, connect the sentence and the complexity of sentences and so on. It is a relatively effective way to expand the speaker's presentation ability and language skills.

\section{RESEARCH DESIGN AND CONCRETE IMPLEMENT}

The author uses the method of public speaking in a real lecture. Before the lecture students are allowed to read a large number of extra-curricular readings, and to find an interesting article or topic. When it is the turn to have the public speaking, student needs to finish a speech within a limited time (usually 3 minutes for speech, 1-2 minutes for answering the question). For example, student can describe a person who he likes or introduce a book or a good movie, and answer the other students' questions after finishing his speech. Finally the teacher should sum up and note the deficiencies of the public speaking.

The public speaking referred in this article is implemented in the specialized courses of Korean department at the Oriental Language and Culture Institute of Qufu Normal University. In the first semester, the freshmen are still in the stage of learning primary Korean, and busy in mastering the pronunciation and simple dialogue. For them, public speaking in Korean will lead the majority of students to have a speech with similar content, and the listeners are easily boring with that kind of speech. Sophomore students relatively adapt to learn the Korean language, but they also need to develop a sense of language. Junior and senior students can already speak everyday Korean fluently, but there are some problems appeared when they want to express their thought in Korean accurately more or less. So, the author presented different requirements of public speaking for different grades.

Specific speaking, in the first semester freshmen's public speaking can be used in Chinese or mixed with English, each student can get five minutes to have their public speaking at the beginning of every lecture (two hours). As a sample of Grade 2008 (include 30 students) which the author taught, each student got twice chances to have the public speaking per semester. The author instructed the other students to note when listening to the speaker, so does the teacher. Thus the teacher can correct the error within 3,5 minutes after public speaking according to the note what he took just now. And guide the other students to give question on the topic what he listened. It can not only improve their presentation skill, but also correct errors and mistakes occurred in their public speaking, and also train the other students' listening, deepen their emotional communication.

Beginning from the second semester, students are demanded to speak in only Korean with an easily understanding content and a reasonable structure. The speaker needs to express clearly, and answer questions simply, logically, also need to leave a deep impression and useful inspiration to the others.

Thinking about most of Junior and Senior students are busy in preparing for the Graduate Test and looking for a job, and some students do really not like to have a public speaking, so when I arrange the speaking task for them, I asked them to give me a name list who really want to have the speech at the first class each semester. At this stage public speaking is carried out one student per week in turn. Due to the long time preparation, so the student is demanded to have an in-depth conversation on a particular topic without the problems such as loose content, much pause, repeat, and inconsistent so on. The aim of public speaking for them is to train them to have continuous speech ability. 
The purpose of Korean language teaching is to improve the student's comprehensive ability, especially the oral expression ability. The method of public speaking has a significant effect on improving the oral expression skills of students. Generally speaking, public speaking needs three stages. Firstly, speaker needs to prepare a topic carefully. The selected topic should be innovative and attract the other students, but also with the professional, combining current events, such as the world economic crisis, South Korea (North Korea) economic, social, cultural and other aspects; Secondly, the speaker needs to elaborate the selected topic with a reasonable structure, a clear and concise language and so on; Thirdly, the speaker needs to answer the others' question in a strong logic way. For the speaker, the above three aspects are the challenges of knowledge, logical thinking, and language skill. From the point of view of the learning process, public speaking is a good way to train and improve students' language skills.

\section{EFFECT ANALYSIS}

After the implement of public speaking for two years, the author made an investigation to analyze the effect of the method. Respondents of the Survey are the students of Grade 2006, 2007 and 2008 in Korean Department, College of Oriental Language \& Culture, Qufu Normal University. Number of questionnaires issued is 89 and number of questionnaires recovered is 65. The content of Questionnaire contains 10 questions including the investigation of its effect on language learning, personal abilities, such as whether it is helpful to the expansion of knowledge. Each question has four answers, it has great help, much help, less help and no help separately. Respondents were asked to only choose one answer. Specific survey content and survey results please see Appendix.

Through analyzing the survey results, we can see that the method of public speaking has great or much help for the students' self-confidence, when the students select the answer of this question, 61 students chose the two kinds of answer mentioned above, accounted for $94 \%$ which is a very good sign. It is impossible to be successful or create miracles with confidence. And self-confidence is very important for foreign language learners, especially self-confidence can bring the positive effects on a speech contest, it can not be ignored. Of course, one speech will not be a successful speech only with the confidence while without the good language skills.

Then what is the effect of the public speaking method on language learning? The questionnaire results show that the method can increase the students' Korean vocabulary and a sense of Korean language, also it is helpful to improve the students' writing skills, listening ability, cognitive ability of grammatical errors. There were 49, 50, 51, 45, 48 students separately chose the answer of great help and more help when they were asked about above-mentioned questions. On the specific point of view, 75\% students felt that the public speaking method can increase their Korean vocabulary. As we know, vocabulary relies on not only the accumulation of memories but also the practice, only the vocabulary is enriched, listening, speaking and translation will be the simple things relatively.

On the improvement of the writing ability and hearing capability, on one hand, 51 and 45 students think that there are great help and much help, accounting for 78\% and 69\% respectively. On the other hand, 12 (accounting for 18\%) and 19 (accounting for 29\%) students felt there is no obvious help for their Korean study. It reflects the method has indirect effects on improving the Korean listening and writing ability. It also shows the method can play a positive role when creating a sense of language, cognitive syntax errors.

With regard to response capability, there are 27 students (accounting for $42 \%$ ) considered it has great help, 24 students (accounting for 37\%) considered that it has much help, 12 students (accounting for 18\%) felt it has no obviously help, and one student (accounting for 2\%) think that there is no help. In addition, 44 students (accounting for $68 \%$ ) felt that public speaking method does helpful to broaden their knowledge. There are 52 students (accounting for $80 \%$ ) who are very fond of this method, and 46 students (accounting for 70\%) felt that they used Korean thinking when they stood on the stage.

Generally speaking, the survey showed that the students' evaluation on public speaking method is positive, students enjoy and participate in this activity actively, it is also an important step to develop their language skills by communicate with the target language. It also can be seen through the survey that the public speaking can broaden students' knowledge, enhance their confidence, promote the Korean language learning and can improve their oral expression.

\section{CONCLUSION}

By implementing the public speaking method, the author found that students' reading ability, listening and speaking ability in Korean has been improved to a large degree, and increased their interesting on studying Korean. It also can put the knowledge what they learned from the textbook into the practice. For the teacher, it is easier to complete teaching purpose effectively, and also helpful to communicate with the students which he taught. But in the actual engagements, we should emphasize the dominant position of students, activate the communication between teachers and students and the interaction between students. It also need to encourage students to innovate and do not let the activity become a mere formality. In short, the ability of oral Korean will not be improved in a short period, and need a long-term exercise properly. Only the teacher try to practice and explore consciously, the students' Korean ability and integrated language ability will be improved. 
APPENDIX A: QUESTIONNAIRE AND ITS SURVEY RESULTS

\begin{tabular}{|c|c|c|c|c|}
\hline Questions & Great Help & Much Help & Less Help & No Help \\
\hline $\begin{array}{l}\text { 1. Public Speaking before Class has } \sim \text { for increasing your Korean } \\
\text { Vocabulary. }\end{array}$ & 10 & 39 & 15 & 1 \\
\hline 2. $\sim$ for expending your knowledge. & 21 & 23 & 19 & 2 \\
\hline 3. $\sim$ for increasing your sense of Korean language. & 21 & 29 & 11 & 2 \\
\hline 4. for increasing confidence to express in Korean. & 37 & 21 & 6 & \\
\hline 7. for increasing self-confidence to take part in a competition. & 40 & 21 & 4 & \\
\hline 8. $\sim$ for recognizing the grammar errors. & 12 & 36 & 16 & 1 \\
\hline 9. for improving your response ability during the stage of Q\&A. & 27 & 24 & 12 & 1 \\
\hline 10. How do you like the method of Public Speaking before class? & $\begin{array}{l}\text { Like it very } \\
\text { much. } \\
18\end{array}$ & $\begin{array}{l}\text { Like it } \\
\text { moderately. } \\
34\end{array}$ & $\begin{array}{l}\text { Don't care } \\
\text { much for it. } \\
8\end{array}$ & $\begin{array}{l}\text { Don't } \\
\text { like it. } \\
3\end{array}$ \\
\hline
\end{tabular}

\section{ACKNOWLEDGEMENT}

The author wish to thank the lovely students who is studying in Korean department of Qufu Normal University, the survey would not have been possible without their support. My thanks also extend to my family, which gave me constant and distant encouragement through the most difficult and challenging times at the beginning of this paper.

\section{REFERENCES}

[1] Cai Yun. (2001). The Role of Panelists Activities in the Foreign Language Learning. Modern Foreign Languages.

[2] Chen Meiei and others. (2004). Exploration and Change: English Teaching in Transition. The Commercial Press.

[3] Duan Ming. (2008). Give Students a Stage Before Class to Show Their English Speaking. Chinese Extramural Education Magazine.

[4] Gass, S. and Selinker, L. (2001). Second Language Acquisition. London: Lawrence Erlbaum Associates, Publishers.

[5] Huang Guangfang. (2003). Exploration and Practice of Presentation within Five Minutes before the Lesson--A Way of Training the Students' Oral English in the University. Journal of Hoon Yang Teachers College. Vol. 23, No. 1.

[6] Huang Qunfang. (2008). A Consideration of the Five Minutes Activities before Lesson. Literary Education.

[7] Krashen, Stephen D. (1988). Second Language Acquisition and Second Language Learning. Prentice-Hall International.

[8] Li Shoujing, Zhou Li. (2002). A Study on Developing Oral English through the Way of Task-centric Speaking. National College English Teaching Symposium. Shanghai Foreign Language Education Press.

[9] Liang Gaiping. (2002). Speaking on Certain Topic in College English Teaching. National College English Teaching Symposium. Shanghai Foreign Language Education Press.

[10] Swain M. (1995). Three Functions of Output in Second Language Learning. Shanghai Foreign Language Education Press.

[11] Wang Liwei. (2007). Let Five Minutes Pre-class Speaking Active the English Teaching. Journal of Guangdong Technical College of Water Resources and Electric Engineering. Vol.5 No.4.

[12] Wilkins, D.A. (1976). Notional Syllabuses: A Taxonomy and its Relevance to Foreign Language Curriculum Development. Oxford: OUP.

[13] Yin Suya. (2005). Public Speaking Education: A Crucial Addition To The English Curriculum Of Chinese Universities. CELEA Journal (Bimonthly). Vol.28 No.4.

[14] Yu Xiaojing, Gong Yuxiang. (2004). Utilizing the Beginning of English Class. Journal of Henan Electrical and Mechanical College. Vol.12, No.2.

[15] Zhong Wenhua. (2003). Put Emphasis on Pre-class lectures, Promote the Students' Quality. Journal of Longyan College. Vol. 21, Supplement.

Lili Pan was born in Shandong, China in 1977. She received her M.A degree from Pukyong National University, Korea in 2004.

She is working in Korean Department at Qufu Normal University (Confucius Culture University) and is the dean of Korean department. She works primarily on the areas of Korean teaching method and she also has research interests in translation and oral interpretation between Chinese and Korean. 